\title{
UMA ANÁLISE DAS COLIGAÇÕES PROPORCIONAIS DE 2010 E $2014^{12}$
}

\author{
Felipe Munhoz de Albuquerque ${ }^{3}$
}

\section{RESUMO}

Este trabalho parte da hipótese já consagrada na literatura de que os partidos políticos são atores racionais, capazes de adotar estratégias pragmáticas, visando a maximização dos seus votos e seu consequente sucesso eleitoral. Pretende analisar as coligações proporcionais nas eleições de 2010 e 2014 a partir dessa ótica. Particularmente, é de nosso interesse estudar as coligações eleitorais realizadas nesses dois pleitos. O objetivo é mostrar que elas efetivamente obedecem um caráter pragmático, com pouca preocupação ideológica. Buscaremos evidenciar as principais características das coligações proporcionais de acordo com algumas variáveis do nosso sistema eleitoral e partidário, como tamanho do partido e do distrito eleitoral, assim como a existência de candidatura no pleito majoritário. Os resultados encontrados deixam claro que as coligações eleitorais são mandatórias para se alcançar o sucesso eleitoral. Elas são inversamente proporcionais ao tamanho do distrito, e são adotadas por partidos de diferentes tamanhos. Isso resulta numa Câmara dos Deputados composta majoritariamente por deputados que se beneficiaram dessa estratégia.
\end{abstract}

Palavras-chave: Sistemas eleitorais. Coligações eleitorais. Partidos políticos.

\begin{abstract}
This work is based on the hypothesis already established in the literature that political parties are rational actors capable of adopting pragmatic strategies, aiming at maximizing their votes and consequent electoral success. It plans to analyze the proportional coalitions in the 2010 and 2014 elections from this perspective. Particularly, it is in our interest to study the electoral coalitions held in these two lawsuits. The aim is to show that they effectively obey a pragmatic character, with little ideological concern. We will try to show the main characteristics of the proportional coalitions according to some variables of our electoral and party system, such as party size and electoral district, as well as the existence of candidacy in the majority election. The results found make it clear that electoral coalitions are mandatory to achieve electoral success. They are inversely proportional to the size of the district, and are adopted by parties of different sizes. This results in a Chamber of Deputies composed largely of Members who have benefited from this strategy.
\end{abstract}

Keywords: Electoral Systems. Pre-electoral coalitions. Political parties,

\section{RESUMO}

Este trabajo parte de la hipótesis ya consagrada en la literatura de que los partidos políticos son actores racionales, capaces de adoptar estrategias pragmáticas, buscando la maximización de sus votos y el consecuente éxito electoral. Pretende analizar las coaliciones proporcionadas en las elecciones de 2010 y 2014 a partir de esa óptica. Particularmente, es de nuestro interés estudiar las coaliciones electorales realizadas en esos dos pleitos. El objetivo es mostrar que ellas efectivamente obedecen un carácter pragmático y con poca preocupación ideológica. Buscaremos evidenciar las principales características de las coaliciones proporcionadas de acuerdo con algunas variables de nuestro sistema electoral y partidario, como tamaño del partido y del distrito electoral, así como la existencia de candidatura en los pleitos mayoritarios. Los resultados encontrados dejan claro que las coaliciones electorales son mandatarios para alcanzar el éxito electoral. Ellas son inversamente proporcionales al tamaño del distrito, y son adoptadas por partidos de diferentes tamaños. Esto resulta en una Cámara de Diputados compuesta mayoritariamente por diputados que se beneficiaron de esa estrategia.

Palabras clave: Sistemas electorales. Coaliciones electorales. Partidos políticos.

\section{INTRODUÇÃO}

As reflexões sobre coligações partidárias no Brasil vêm numa trajetória crescente.

Desde o primeiro trabalho que se propôs a estudar de forma sistemática as então chamadas

\footnotetext{
${ }^{1}$ DOI: http://dx.doi.org/10.5380/recp.v8i2.56299

${ }^{2}$ Submetido em: 30 de setembro de 2017. Aprovado em: 15 de outubro de 2017.

${ }^{3}$ Doutorando em Ciência Política pelo Instituto de Estudos Sociais e Políticos (IESP), da Universidade do Estado do Rio de Janeiro (UERJ). Mestre em Ciência Política pela mesma instituição. E-mail: felipeaqq@gmail.com.
} 
"alianças" (SOARES, 1964), diversas foram as pesquisas realizadas que buscaram entender essa dinâmica. Três são os direcionamentos das principais correntes de estudo a esse respeito: uma que enfatiza as motivações e incentivos para a formação de coligações; a que visa fazer uma classificação das coligações; e as que analisam a relação entre estratégias coligacionistas e nacionalização partidária. A primeira corrente busca responder quando e por que vale a pena se coligar. A segunda se debruça sobre o perfil das coligações — se elas são ideologicamente consistentes e estáveis ao longo do tempo ou se obedecem a uma lógica ligada ao apoio ou não ao executivo. A terceira analisa a influência das direções partidárias nacionais ou das eleições presidenciais nas estratégias de coligação nas eleições estaduais.

Segundo Krause e Schmitt (2005), o desenvolvimento das pesquisas sobre as coligações eleitorais permite desde a realização de uma crítica acerca do sistema partidário brasileiro até as análises das estratégias dos partidos políticos em munícipios, estados ou regiões. Este trabalho não tem anseios tão grandes. Seu propósito é expor como se deram as estratégias partidárias quanto à formação de coligações nas eleições para a Câmara dos Deputados em 2010 e 2014. Para isso, primeiro será feita uma apresentação da legislação eleitoral e do problema proporcionado pelas coligações. Posteriormente, será realizada uma breve análise da literatura sobre o tema. Não serão, no entanto, expostos todos os debates a esse respeito - principalmente quanto às questões ideológicas das alianças eleitorais —, dando-se prioridade ao âmbito pragmático embutido nelas. Por fim, será realizada uma análise dos dados referentes às alianças consumadas pelos partidos em 2010 e em 2014 ${ }^{4}$, buscando-se testar as principais hipóteses apresentadas pela literatura tradicional sobre o tema.

Em relação às coligações, a principal hipótese adotada neste trabalho é a de que o objetivo maior de qualquer legenda no momento de definir entre participar de uma coligação ou competir individualmente é o de maximizar o número de votos - maximização esta no sentido de conquistar um maior número de cadeiras no Legislativo. Os principais fatores que entram no cálculo são a magnitude do distrito e o tamanho do partido.

\section{AS COLIGAÇÕES NAS ELEIÇÕES BRASILEIRAS}

Aparecendo pela primeira vez no Código Eleitoral de 1932 — tendo como um dos seus elaboradores o próprio Assis Brasil —, a representação proporcional passou a ser integralmente adotada a partir de 1945. Desde então, todas as eleições para a Câmara dos Deputados foram

\footnotetext{
${ }^{4}$ Dados coletados no repositório de dados eleitorais, no site do TSE.
} 
por ela regidas, com poucas mudanças ao longo do tempo ${ }^{5}$. A sua função é garantir que cada partido receba um número de cadeiras na disputa proporcional à sua votação; é possibilitar que os integrantes do corpo representativo sejam proporcionais ao conjunto de preferências eleitorais existentes na sociedade. Para que haja essa proporcionalidade de representação, são diversas as fórmulas eleitorais existentes, divididas em dois grupos: "maiores sobras" e "maiores médias".

No Brasil, a distribuição das vagas é feita da seguinte forma: primeiramente, é calculado o quociente eleitoral de cada estado (distrito), a partir da cota Hare de maiores sobras, dividindo-se a quantidade de votos válidos no distrito pelo número de vagas disponíveis. $\mathrm{O}$ quociente dessa divisão seria o "custo" mínimo de votos necessários para uma cadeira. Em um segundo momento, divide-se os votos de cada partido pelo quociente eleitoral. Os números inteiros resultantes dessas divisões são a quantidade de cadeiras iniciais a que cada partido tem direito. O quociente eleitoral funciona também como uma cláusula de barreira, excluindo-se da disputa os partidos que não o alcançam. Por fim, as cadeiras que não foram distribuídas são preenchidas de acordo com o método D’Hondt de maiores médias: o total de votos de cada partido é dividido pelo número de cadeiras obtidas pelo quociente eleitoral na primeira divisão acrescido de um. O partido que obtiver a maior média conquista a vaga. O procedimento é repetido até que todas as vagas sejam preenchidas.

Com a definição das bancadas partidárias, o passo seguinte no processo eleitoral é saber quais são os candidatos que ficarão com as cadeiras. São dois os principais métodos para definir quem preencherá esses lugares: listas abertas e listas fechadas. Elas diferem entre si a respeito do controle partidário na escolha dos políticos que serão apresentados ao eleitorado. $\mathrm{Na}$ lista fechada, os partidos definem, antes das eleições, o ordenamento dos candidatos. $\mathrm{O}$ eleitor não vota em nomes, mas apenas nas legendas. As cadeiras que cada partido eleger serão ocupadas pelos primeiros nomes da lista. No sistema de lista aberta, quem decide que candidatos ocuparão as cadeiras são os eleitores. Ao eleitor é facultado votar no candidato de sua preferência ou, em alguns países, como o Brasil, na legenda. Todos esses votos são somados e os candidatos mais votados individualmente são eleitos. Dessa forma, as listas abertas estimulam a competição entre os membros de uma mesma legenda — segundo Nicolau (2006),

\footnotetext{
${ }^{5}$ Em 1950 foi alterada a regra de distribuição de cadeiras não ocupadas na primeira alocação, adotando-se o método D'Hondt de maiores médias. No período da Ditadura Militar foram proibidas as coligações eleitorais, que só voltaram a ser autorizadas após a redemocratização. Em 1998, os votos em branco foram excluídos do cálculo do quociente eleitoral.
} 
"como a alocação intralista é feita pelo sistema majoritário, os candidatos têm como principais adversários os colegas da própria lista e não de outros partidos".

A grande questão em todo esse procedimento é que no Brasil é permitida a formação de coligações partidárias. Nicolau aponta que nos países em que são permitidas coligações eleitorais (Brasil, Finlândia, Israel, Bélgica e Suíça, por exemplo) existem duas maneiras de distribuição de cadeiras: "A primeira faz uso de uma fórmula segundo a qual cada partido recebe um número de cadeiras proporcional à contribuição que ele deu para a votação total da coligação" (NICOLAU, 2012, p.60), ou seja, distribui de forma proporcional as cadeiras também dentro das coligações. Assim, um partido que contribuiu, por exemplo, com $20 \%$ dos votos da coligação, tem direito a $20 \%$ das cadeiras conquistadas por ela. Mas esse não é o caso brasileiro. No Brasil, a distribuição das cadeiras se dá do segundo modo: a legislação eleitoral considera as coligações como um "partido único ou provisório" (FLEISCHER; DALMORO, 2005, p. 89).

Sendo assim, respeitando-se a regra da lista aberta, os mais votados da coligação, independentemente do partido aos quais são filiados, são os eleitos. Para obter uma cadeira, portanto, o partido não precisa receber um grande número de votos, mas garantir que seus candidatos estejam entre os mais votados da coligação. Os candidatos da coligação competem não só com os outros candidatos do próprio partido, mas com todos os candidatos da coligação, como em uma “cesta única” (FLEISCHER; DALMORO, 2005, p. 133).

Duas são as consequências desse desenho institucional. Em primeiro lugar, não são os partidos coligados que precisam ultrapassar o quociente eleitoral para aspirarem às vagas em disputa, mas sim as coligações. Isso permite que partidos pequenos - que se competissem sozinhos seriam limados da disputa - consigam efetivamente concorrer a uma das vagas. Essa disposição deturpa o viés majoritário da corrida eleitoral. Partidos que concorrem sozinhos e não alcançam o quociente eleitoral não conquistam nenhuma vaga; partidos coligados que também não alcançam o quociente eleitoral podem acabar conquistando cadeiras ${ }^{6}$.

A segunda consequência reflete na estratégia de lançamento de candidaturas pelos partidos. Eles não precisam ter uma grande proporção de votos em relação ao resto da coligação para que tenham um candidato eleito, mas apenas posicionar seus candidatos entre os mais votados da lista partidária. Para isso, o partido pode concentrar seus votos em um ou dois aspirantes a uma vaga, contando que outros partidos façam o "trabalho sujo" de aumentar a quantidade de votos da coligação.

\footnotetext{
${ }^{6}$ Paiva, Alves e Benedito (2016) constatam em um trabalho recente que partidos pequenos conseguem se adaptar às regras do jogo estadual e efetivamente obtém maior sucesso eleitoral quando concorrem coligados.
} 


\section{RECUPERAÇÃO DA LITERATURA}

Nas pesquisas sobre coligações eleitorais no Brasil, a maioria dos trabalhos costuma, grosso modo, combinar diferentes doses de dois eixos explicativos principais. De um lado, há os que apontam a prevalência do pragmatismo como mola propulsora das coligações: o partido constrói alianças para minimizar custos e maximizar suas chances eleitorais, desconsiderando a coloração ideológica dos parceiros necessários para a vitória. Do outro lado, há a perspectiva que coloca a ideologia como freio ao leque de alianças: o alcance das alianças de um partido — também visando maximizar suas chances eleitorais — é restringido por seu matiz ideológico e pelo de seus parceiros.

As duas visões foram sistematizadas primeiramente por Gláucio Soares (1964), em seu artigo "Alianças e coligações eleitorais: notas para uma teoria”. Soares constata a crescente importância das coligações ao longo das eleições para a Câmara dos Deputados. Segundo ele, "os votos dados às alianças e coligações cresceram continuamente em cifras absolutas e relativas de eleição para eleição, a ponto de constituírem um elemento perturbador nas análises comparativas do apoio recebido pelos diversos partidos" (SOARES, 1964, p. 95).

$\mathrm{Na}$ sua teoria da economia de esforços, Soares supõe que, conhecidas as regras institucionais das eleições parlamentares, os partidos agirão racionalmente, formando alianças eleitorais que os ajudem a maximizar seus desempenhos. Desta teoria surgem três hipóteses a respeito de quais situações seriam propícias para a formação de coligações: a) os pequenos partidos têm maior interesse em se aliarem do que os partidos maiores, já que para eles é mais difícil atingir o quociente eleitoral; b) há mais alianças nas eleições para a Câmara dos Deputados do que nas eleições para as Assembleias Legislativas, uma vez que é maior o quociente eleitoral no primeiro caso $^{7}$; e c) as alianças são mais frequentes nas eleições majoritárias do que nas proporcionais.

Junto com a teoria da economia de esforços, o autor propõe a teoria da resistência ideológica, que, como a anterior, fez parte da primeira análise feita sobre o papel que a ideologia tinha na formação de alianças. De caráter mais sociológico, ela supõe que eleitores urbanos possuem uma maior orientação ideológica e, portanto, são mais resistentes à formação de alianças, já que são mais politizados. Ela é mais atenta às características socioeconômicas dos partidos e de suas bases sociais e resulta em duas hipóteses: d) as alianças são mais comuns nos

\footnotetext{
${ }^{7}$ Como o quociente eleitoral é a quantidade de votos válidos dividido pela magnitude (número de vagas em disputa) do distrito, quanto menor a magnitude, maior o quociente eleitoral, e mais desproporcional é o sistema.
} 
estados rurais do que nos urbanos; e e) partidos com ideologia definida e com base social nítida formariam menos alianças.

Os estudos posteriores, munidos de mais eleições e métodos mais avançados de análise, corroboraram a primeira visão. O entendimento construído pela literatura subsequente é o de que os partidos pequenos se coligam e concentram seus recursos em poucos candidatos, visto que a distribuição de cadeiras beneficia não os partidos mais votados, mas os candidatos mais votados, enquanto partidos grandes aceitam se coligar com os pequenos para outros fins - como derrotar seus principais adversários, a universalização do bônus (com todos os partidos, em algum momento, sendo beneficiados por esse mecanismo) (SANTOS 1987), ter instrumentos de barganha para conseguir apoio nas eleições majoritárias estaduais e nacionais (LAVAREDA 1991), a maximização de votos (seguindo-se uma "lei de ferro da competição eleitoral"8) (FIGUEIREDO 1994) e o tempo no Horário Gratuito de Propaganda Eleitoral (HGPE) (NICOLAU 1996).

Mais recentemente, outras variáveis passaram a ser acrescidas às teorias explicativas sobre as coligações. O posicionamento do partido frente aos governos de diversos níveis governismo versus oposicionismo - e seu comportamento coligacionista pregresso e/ou nas demais arenas são fatores apontados pelos especialistas como possíveis limitadores à adoção de estratégias exclusivamente calculistas e pragmáticas para a celebração de coligações (SCHMITT, 1999; MACHADO; MIGUEL, 2007).

Visto isso, o objetivo dos partidos que se coligam têm caráter temporário, qual seja, garantir vantagens nos resultados eleitorais. Imbuídas de uma racionalidade instrumental, essas alianças são apenas um mecanismo para se chegar a determinado fim, não fazendo sentido que sejam duráveis. Da mesma forma, visto o caráter pragmático que elas contêm, o espectro ideológico e a dualidade esquerda/direita não devem ser os fatores mais importantes no momento da definição dos partidos que formação esse acordo pré-eleitoral.

Porém isso não significa que essas motivações sejam inexistentes. Dessa forma, a "lei de ferro da competição eleitoral" é adaptada a essa questão. Em eleições mais desproporcionais - no caso do sistema proporcional, as eleições com magnitude baixa, e, portanto, quociente eleitoral alto - os partidos querem primeiro diminuir as chances de derrota nas urnas. Os partidos pequenos, portanto, não se sentirão constrangidos em se coligar com partidos do campo

\footnotetext{
${ }^{8}$ De modo mais geral, partidos políticos formariam alianças sempre que essa estratégia fosse capaz de reduzir o risco de se perder uma eleição. Em condições mais favoráveis, ou seja, quando as chances de derrota são menores, a necessidade de participar de alianças diminui, com os partidos tendo uma maior margem de manobra.
} 
ideológico oposto. A quantidade de coligações inconsistentes para as eleições ao Legislativo nesses estados deve ser alta. No sentido oposto, eleições em estados com mais cadeiras em disputa diminuem a chance de derrota nas urnas, contando com um quociente eleitoral mais fácil de ser ultrapassado pelos partidos. Nesse sentido, os partidos têm mais liberdade para buscarem alianças junto a partidos com ideologias mais próximas.

Com as eleições casadas para os executivos e legislativos federais e estaduais, alguns estudos se dispuseram a procurar uma relação entre as alianças eleitorais em diversas esferas ${ }^{9}$. Porém, de acordo com Lima Junior (1983), as organizações partidárias respondem mais a questões locais do que nacionais. Da mesma forma que o federalismo partidário rege a formação de coligações nos estados, rege também o desenho dos diferentes sistemas partidários locais. Dessa forma, nem sempre um partido grande nacionalmente é grande em todos os estados, da mesma forma que um partido pequeno na Câmara Federal, como um todo, pode ser grande em determinada região. Trabalhos mais recentes corroboram a opção pelo caminho escolhido. Tanto as análises que buscam comprovar o caráter pragmático das coligações quanto aquelas que estudam o tema a partir de uma visão relacionada à identidade ideológica alcançam, costumeiramente, as mesmas conclusões. Aline Machado (2005) e Borges, Carreirão e Nascimento (2016), por exemplo, encontram como "estimulantes" para a formação das coligações o tamanho da magnitude ou dos partidos, ficando em segundo plano a identidade ideológica. Krause e Godoi (2010) e Miranda (2016), olhando para as eleições para governadores, também entendem a orientação pela maximização do voto como princípio geral. Machado e Miguel (2010), analisando a esfera municipal, veem este comportamento ocorrendo inclusive no PT, um dos partidos que, na década de 90, tinha grandes resistências a construir alianças com partidos distantes do seu espectro ideológico.

\section{ANÁLISE DE 2010 E 2014}

A nossa legislação eleitoral contém certas características que tornam as eleições mais ou menos proporcionais. A variação da magnitude dos distritos, dependendo do estado em questão, faz com que algumas eleições — como a de São Paulo, com 70 cadeiras — sejam bastante proporcionais, enquanto estados com menor magnitude tendem a ser mais desproporcionais. O nosso quociente eleitoral funciona como uma cláusula de barreira, excluindo da disputa diversos partidos que não conseguem alcançá-lo, principalmente nos

\footnotetext{
${ }^{9}$ Krause (2005)(2005)(2005) propõe um bom debate sobre esse assunto.
} 
distritos menores. A própria fórmula D’Hondt, embora proporcional, favorece mecanicamente os maiores partidos ${ }^{10}$. As regras referentes às coligações conseguem torná-las estratégias eficientes dos partidos para driblar essas distorções da legislação eleitoral e maximizar os seus votos. Os incentivos para estarem em uma coligação são de longe maiores do que os seus possíveis prejuízos.

As principais hipóteses levantadas pela literatura, e que servirão de guia para o restante deste artigo, são:

a) Hipótese 1 - Em uma de suas proposições de similaridade, Rae (1957) diz que a proporcionalidade na alocação de cadeiras em um determinado distrito aumenta de acordo com a magnitude do distrito. Por associação, quanto menor a magnitude do distrito, mais desproporcional será o sistema. Isso se dá, em grande parte, pelo "custo" de entrada na disputa, ou o quociente eleitoral. Distritos menores, portanto, tendem a punir partidos que não forem bem votados. Visto isso, quanto menor a magnitude do distrito, maior a ocorrência de coligações.

b) Hipótese 2 - Da mesma forma, por terem um alto custo de entrada na disputa, os partidos pequenos buscarão formar coligações maiores, com vistas a alcançar uma grande proporção de votos, aumentando as chances de elegerem seus candidatos. Dessa forma, quanto menor for o distrito, maiores serão as coligações. Como alcançar o quociente eleitoral se torna mais fácil à medida que aumenta a magnitude do distrito, o tamanho médio das coligações tende a diminuir com o aumento da magnitude do distrito.

c) Hipótese 3 - A associação entre o tamanho do partido e a formação de coligação é negativa. Partidos maiores - no estado - têm uma maior facilidade de ultrapassar o quociente eleitoral, por terem uma maior proporção de votos. Enquanto, para eles, o maior incentivo para se coligar é concorrer por mais vagas, partidos pequenos têm a necessidade de se coligar para conseguir ultrapassar o quociente eleitoral e disputar uma vaga.

d) Hipótese 4 - As coligações proporcionais são um subproduto das coligações majoritárias. Só podem ser formadas coligações nas eleições para a Câmara dos Deputados entre partidos que participam da mesma chapa para governador. De um lado, partidos grandes precisam do tempo de HGPE dos partidos pequenos para se fortalecerem na disputa pelo Executivo e, de outro, os partidos pequenos barganham apoio com sua

\footnotetext{
${ }^{10}$ Benoit (2000) faz um interessante estudo sobre este tema, simulando a proporcionalidade de diversas fórmulas eleitorais. Sua conclusão é a de que elas variam de acordo com a magnitude do distrito. No caso do método D'Hondt, Benoit segue a literatura tradicional, que a considera uma das fórmulas proporcionais com maior viés majoritário, mas que, com o aumento da magnitude, se torna tão proporcional quanto as outras.
} 
inclusão na aliança proporcional. Dessa forma, partidos cabeças de chapa nas eleições majoritárias usualmente participam de coligações proporcionais com a maioria dos partidos aliados nas eleições para governador.

\section{RÁPIDAS QUESTÕES METODOLÓGICAS}

A legislação eleitoral define como oito o número mínimo de deputados por estado, e setenta o seu máximo. Para a análise dos dados, será utilizada a mesma categorização proposta por Schmitt (1999), que divide as magnitudes eleitorais brasileiras em baixa, média e alta. Os estados de magnitude baixa são os que contam com 8 deputados (AC, AM, AP, DF, MS, MT, RN, RO, RR, SE e TO). Os que têm de 9 a 20 deputados (AL, ES, GO, MA, PA, PB, PI e SC) são considerados de magnitude média, e os de alta magnitude são os que têm de 22 a 70 deputados (BA, CE, MG, PE, PR, RJ, RS e SP).

Quanto ao tamanho dos partidos, a regra do jogo é clara: para que um partido ganhe uma cadeira, é necessário que ele alcance o quociente eleitoral. Portanto, o critério para classificar os partidos de acordo com a sua grandeza gira em torno de tal quociente. São considerados grandes os partidos que conseguem, por conta própria, ultrapassar o quociente eleitoral. Partidos médios são aqueles que não alcançam o quociente, mas conseguem uma votação relevante no estado, com pelo menos $50 \%$ do quociente eleitoral. Partidos pequenos são aqueles que não alcançam nem a metade da votação necessária para atingir o quociente eleitoral.

\section{QUADRO 1 - TAMANHO DO PARTIDO DE ACORDO COM O QUOCIENTE ELEITORAL}

\begin{tabular}{|c|c|}
\hline Tamanho do partido no estado & Votação em relação ao quociente eleitoral \\
\hline Grande & Superior ao quociente eleitoral \\
\hline Médio & Acima de $50 \%$ do quociente eleitoral \\
\hline Pequeno & Abaixo de $50 \%$ do quociente eleitoral \\
\hline
\end{tabular}

FONTE: TRIBUNAL SUPERIOR ELEITORAL.

\section{FREQUÊNCIA DAS COLIGAÇÕES}

Seguindo a nossa linha de raciocínio, é esperado que a formação de coligações tenha um caráter essencialmente pragmático, com os partidos se coligando para obter um maior sucesso eleitoral. Em estados com menos cadeiras em disputa, é proporcionalmente mais difícil eleger algum deputado e, portanto, os partidos contam com maiores incentivos para se coligarem. Em estados maiores, a chance de se ultrapassar o quociente eleitoral — em termos 
proporcionais - é maior. Consequentemente, espera-se que ocorra um menor número de alianças eleitorais. A Tabela 1 discrimina os partidos, quando competem coligados, de acordo com a sua magnitude:

\section{TABELA 1 - PARTICIPAÇÃO DE PARTIDOS NAS ELEIÇÕES LEGISLATIVAS FEDERAIS POR MAGNITUDE DISTRITAL (2010 E 2014)}

\begin{tabular}{|c|c|c|c|c|c|c|}
\hline \multirow{3}{*}{$\begin{array}{l}\text { Magnitude } \\
\text { do distrito }\end{array}$} & \multicolumn{3}{|c|}{2010} & \multicolumn{3}{|c|}{2014} \\
\hline & \multicolumn{2}{|c|}{ Partidos em coligações } & \multirow{2}{*}{$\begin{array}{l}\text { Total de } \\
\text { partidos }\end{array}$} & \multicolumn{2}{|c|}{ Partidos em coligações } & \multirow{2}{*}{$\begin{array}{l}\text { Total de } \\
\text { partidos }\end{array}$} \\
\hline & $\mathrm{n}^{\mathrm{o}}$ & $\%$ & & $\mathrm{n}^{\mathrm{o}}$ & $\%$ & \\
\hline Baixa & 232 & 90,6 & 256 & 298 & 91,7 & 325 \\
\hline Média & 169 & 87,5 & 193 & 205 & 87,6 & 234 \\
\hline Alta & 148 & 72,9 & 203 & 202 & 81,1 & 249 \\
\hline Total & 549 & 84,2 & 652 & 705 & 87,2 & 808 \\
\hline
\end{tabular}

FONTE: TRIBUNAL SUPERIOR ELEITORAL.

No geral, a proporção de partidos que concorrem coligados sobre o total de concorrentes é bem alta. Em 2010, corroborando a Hipótese 1, estados com baixa magnitude tiveram uma maior proporção de partidos coligados, com aproximadamente $90 \%$ das organizações partidárias construindo alianças. Em estados de média magnitude, a taxa decresce um pouco, mas continua alta, com $87,5 \%$ de partidos coligados. Estados com uma grande quantidade de deputados contaram com quase $73 \%$ dos partidos em alguma aliança. $\mathrm{O}$ ano de 2014 conta com características semelhantes: os estados de baixa e média magnitude continuaram com aproximadamente os mesmos índices. Os estados de alta magnitude permaneceram sendo os que contam com a menor proporção de partidos coligados, porém aumentando sua proporção para $81,1 \%$.

A Tabela 2 desagrega a frequência de legendas coligadas por estado, com aqueles que tiveram um aumento na proporção de partidos coligados em cinza. Exceto por São Paulo, todos os estados apresentaram um aumento na proporção de partidos coligados. Em alguns casos, como Ceará, Pernambuco e Minas Gerais, quase todas as legendas optam por participar de alianças $^{11}$.

\footnotetext{
${ }^{11}$ No Ceará, apenas o PSB optou por concorrer sozinho. Nos outros dois estados, apenas o PSOL e o PSTU não se coligaram.
} 
TABELA 2 - PROPORÇÃO DE PARTIDOS COLIGADOS POR ESTADO

\begin{tabular}{|c|c|c|c|c|c|c|c|c|c|c|c|}
\hline Magnitude & Estado & 2010 & 2014 & Magnitude & Estado & 2010 & 2014 & Magnitude & Estado & 2010 & 2014 \\
\hline \multirow{11}{*}{ 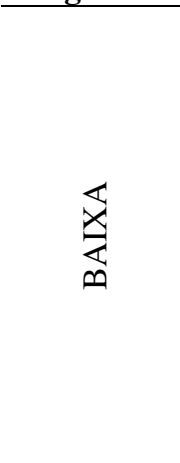 } & RR & 0,91 & 1 & \multirow{11}{*}{ 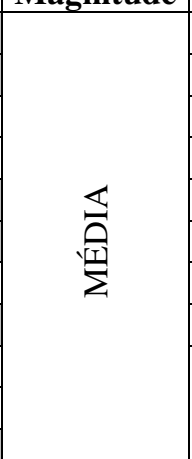 } & $\mathrm{AL}$ & 0,96 & \begin{tabular}{|l|l}
0,96 \\
\end{tabular} & \multirow{11}{*}{$\underset{⿱ 乛}{\stackrel{4}{\rightleftarrows}}$} & $\mathrm{CE}$ & \begin{tabular}{|l|l|}
0,84 \\
\end{tabular} & \begin{tabular}{|l|}
0,97 \\
\end{tabular} \\
\hline & $\mathrm{AP}$ & 0,92 & 0,96 & & PI & 0,76 & 0,9 & & PE & 0,81 & \begin{tabular}{|l|l|}
0,94 \\
\end{tabular} \\
\hline & $\mathrm{AC}$ & 1 & 0,96 & & ES & 0,96 & \begin{tabular}{|l|l|}
0,97 \\
\end{tabular} & & PR & 0,69 & \begin{tabular}{|l|l|}
0,71 \\
\end{tabular} \\
\hline & $\mathrm{TO}$ & 1 & 0,93 & & PB & 0,84 & 0,83 & & RS & 0,68 & 0,8 \\
\hline & RO & 0,96 & 0,97 & & GO & 1 & 0,83 & & BA & 0,79 & \begin{tabular}{|l|l}
0,87 \\
\end{tabular} \\
\hline & SE & 0,83 & 0,9 & & MA & 0,88 & 0,87 & & $\mathrm{RJ}$ & 0,62 & \begin{tabular}{|l|l}
0,72 \\
\end{tabular} \\
\hline & MS & 0,96 & 0,9 & & SC & 0,76 & 0,77 & & MG & 0,8 & \begin{tabular}{|l|l|}
0,94 \\
\end{tabular} \\
\hline & $\mathrm{DF}$ & 0,8 & 0,88 & & PA & 0,87 & 0,87 & & SP & 0,6 & 0,56 \\
\hline & AM & 0,85 & 0,81 & & & & & & & & \\
\hline & MT & 0,9 & 0,89 & & & & & & & & \\
\hline & $\mathrm{RN}$ & 0,87 & 0,9 & & & & & & & & \\
\hline
\end{tabular}

FONTE: TRIBUNAL SUPERIOR ELEITORAL.

\section{TAMANHO DAS COLIGAÇÕES}

Embora a frequência de coligações seja maior à medida que diminui a magnitude dos distritos, no geral ela é relativamente alta. Partidos normalmente optam por se coligar independentemente do estado em que estejam competindo. Porém, o perfil das coligações dificilmente será o mesmo. Em estados grandes, os partidos possuem uma margem maior de ação no momento de montar a coligação. O viés majoritário é consideravelmente menor, resultando em eleições mais proporcionais. Dessa forma, não é necessário se coligar com muitos partidos. Já em estados menores, o viés majoritário pune os partidos ou coligações com poucos votos. Nesses casos, as legendas buscam formar alianças mais amplas.

A Figura 1 mostra a média de tamanho das coligações por magnitude. Em 2010, as coligações tiveram, em média, 6,57 partidos. A associação entre o tamanho da coligação e a magnitude é negativa: quanto menor a magnitude, maior o tamanho médio das coligações. Nos estados de baixa magnitude, a média foi de 7,49 partidos por coligação, enquanto nos estados de média magnitude ela passa para 6,71 partidos. Em estados com magnitudes altas encontramos a menor média, de aproximadamente 5 partidos por coligação. Em 2014, o padrão permaneceu inalterado: houve um aumento geral no tamanho das coligações, passando de 6,57 para 7,85 partidos. Nos três tipos de magnitude houve um aumento médio no número de partidos por coligação, passando-se para 9 partidos por coligação nos estados menores, 8 nos estados de magnitude média e aproximadamente 6 nos maiores estados. 


\section{FIGURA 1 - TAMANHO MÉDIO DAS COLIGAÇÕES POR MAGNITUDE}

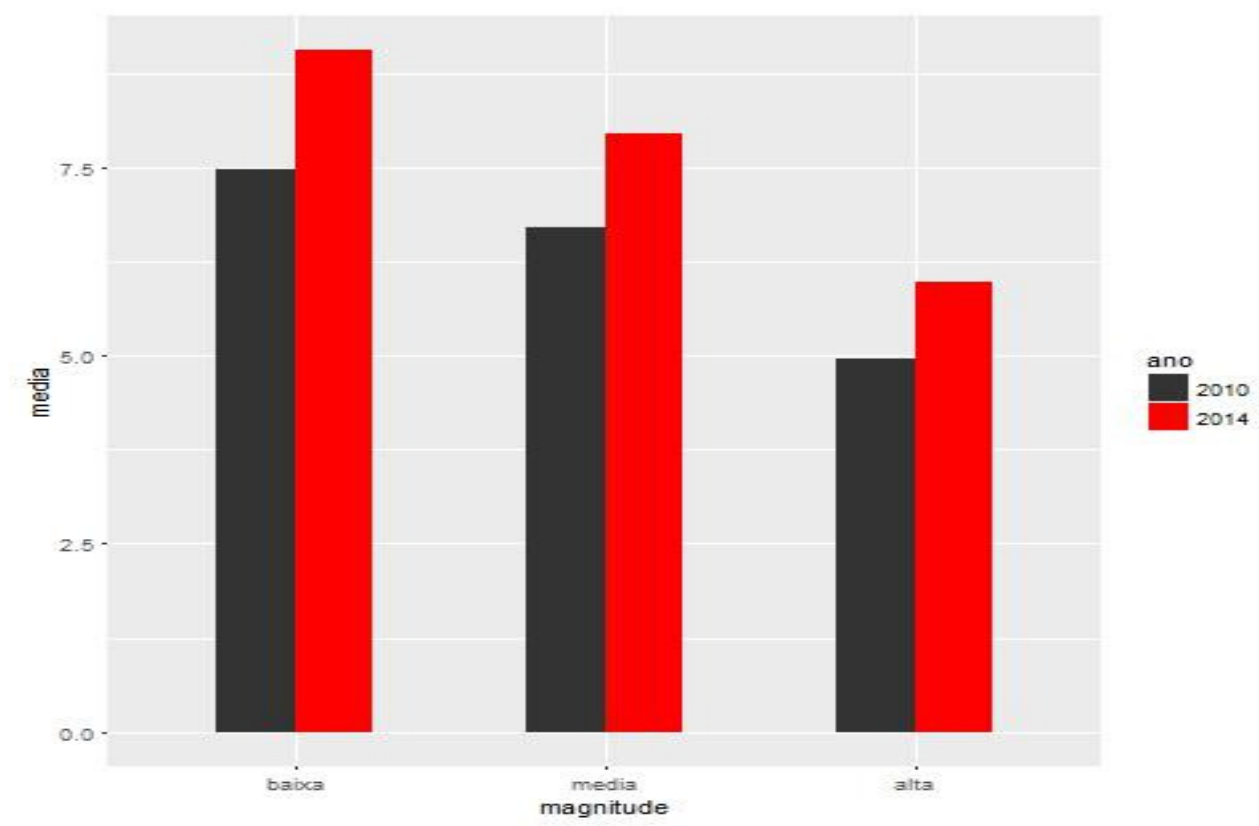

FONTE: TRIBUNAL SUPERIOR ELEITORAL.

Nas eleições de 2014, não só houve uma maior proporção de partidos coligados, como eles formaram alianças maiores. Dos 27 estados brasileiros, apenas 8 apresentaram um número de partidos por coligação menor do que nas eleições anteriores (Tabela 2). Não pode ser descartada, porém, a possibilidade de esse crescimento no tamanho das alianças nessas duas eleições ser uma consequência do surgimento de novos partidos de tendências coligacionistas.

Em alguns estados dentre os quais ocorreu um acréscimo na média de tamanho das coligações, ela foi discrepante em relação à tendência geral. Em Sergipe, a média passou de 5,95 para 11,3 partidos por coligação. Na Paraíba, ela passa de 7,38 para 12,68, e, em Pernambuco, de 6,43 para 10,38. Nesses três estados foram montadas coligações muito maiores do que a média da última eleição, provavelmente buscando-se diminuir o número de cadeiras conquistadas pelos partidos rivais e, consequentemente, a força desses partidos no estado. Nesses três casos, houve uma concentração das coligações na disputa entre PT e PSDB-PSB. 
TABELA 3 - TAMANHO MÉDIO DAS COLIGAÇÕES POR ESTADO

\begin{tabular}{|c|c|c|c|c|c|c|c|c|c|c|c|}
\hline Magnitude & Estado & 2010 & 2014 & Magnitude & Estado & 2010 & 2014 & Magnitude & Estado & 2010 & 2014 \\
\hline \multirow{11}{*}{ 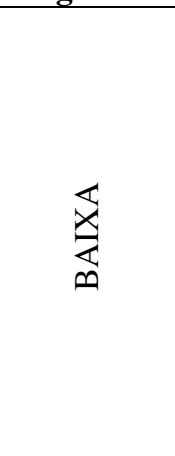 } & $\mathrm{AC}$ & 11,82 & 11,3 & \multirow{8}{*}{ 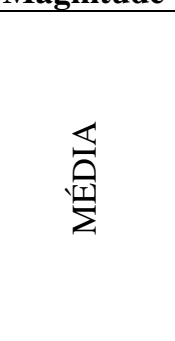 } & $\mathrm{AL}$ & 6,3 & 8,11 & \multirow{8}{*}{ 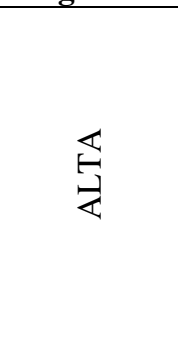 } & $\mathrm{CE}$ & 5,95 & 7,33 \\
\hline & AM & 9,18 & 13 & & ES & 6,45 & 5,53 & & $\mathrm{PE}$ & 6,43 & 10,38 \\
\hline & AP & 6,27 & 6,26 & & PI & 6,79 & 9,37 & & PR & 4,56 & 6,64 \\
\hline & $\mathrm{DF}$ & 6,3 & 6,64 & & PB & 7,38 & 12,68 & & $\mathrm{RS}$ & 5 & 5,42 \\
\hline & MS & 7,78 & 5,96 & & $\mathrm{SC}$ & 7,21 & 9,75 & & BA & 6,47 & 6,23 \\
\hline & MT & 5,21 & 6,6 & & $\mathrm{GO}$ & 6,36 & 7,32 & & RJ & 3,5 & 3,17 \\
\hline & $\mathrm{RN}$ & 4,1 & 9,69 & & $\mathrm{PA}$ & 6,9 & 6,38 & & MG & 3,7 & 3,87 \\
\hline & $\mathrm{RO}$ & 7,17 & 8,64 & & MA & 6,43 & 5 & & SP & 3,4 & 3,44 \\
\hline & RR & 7,29 & 7,93 & & & & & & & & \\
\hline & SE & 5,95 & 11,3 & & & & & & & & \\
\hline & TO & 10,52 & 12,64 & & & & & & & & \\
\hline
\end{tabular}

FONTE: TRIBUNAL SUPERIOR ELEITORAL.

\section{TAMANHO DOS PARTIDOS}

Os grandes partidos nacionais não são necessariamente grandes em todos os estados. Retomando a ideia de racionalidade política contextual, há diversos subsistemas partidários estaduais. Assim, o tamanho dos partidos será aqui considerado no nível estadual, e não nacional. Os estudos que testam a relação entre o tamanho dos partidos e a prática de coligações normalmente fazem essa "medição" no âmbito nacional, de forma que não fica tão claro como os partidos relevantes no estado se comportam.

A Tabela 4 mostra a frequência de coligações por tamanho de partido. Tanto em 2010 como em 2014, 144 legendas alcançaram o quociente eleitoral e foram consideradas grandes. Em 84\% das vezes em 2010 e $87 \%$ em 2014, tais legendas optaram por concorrer com algum outro partido. Partidos médios foram os que mais buscaram se coligar: em cada ano, apenas 3 partidos medianos preferiram disputar sozinhos pelas vagas. Partidos pequenos foram, proporcionalmente, os que menos se coligaram nos dois anos.

\section{TABELA 4 - FREQUÊNCIA DE PARTIDOS COLIGADOS POR TAMANHO DO PARTIDO}

\begin{tabular}{|c|c|c|c|c|c|c|}
\hline \multirow{3}{*}{$\begin{array}{c}\text { Tamanho } \\
\text { do partido }\end{array}$} & \multicolumn{3}{|c|}{2010} & \multicolumn{3}{|c|}{2014} \\
\hline & \multicolumn{2}{|c|}{ Coligação } & \multirow[t]{2}{*}{$\begin{array}{l}\text { Total de } \\
\text { partidos }\end{array}$} & \multicolumn{2}{|c|}{ Coligação } & \multirow[t]{2}{*}{$\begin{array}{l}\text { Total de } \\
\text { partidos }\end{array}$} \\
\hline & $\mathrm{n}^{\mathrm{o}}$ & $\%$ & & $\mathrm{n}^{\mathrm{o}}$ & $\%$ & \\
\hline Grande & 122 & 84,7 & 144 & 126 & 87,5 & 144 \\
\hline Médio & 89 & 96,7 & 92 & 119 & 97,5 & 122 \\
\hline Pequeno & 338 & 81,3 & 416 & 460 & 84,9 & 542 \\
\hline
\end{tabular}

FONTE: TRIBUNAL SUPERIOR ELEITORAL. 
O que representa este comportamento? Em primeiro lugar, a preferência dos partidos grandes por concorrerem coligados. Eles não precisam se aliar a outros partidos para elegerem seus candidatos, já que, ao ultrapassarem os quocientes eleitorais, elegem pelo menos um candidato e participam da distribuição das sobras. Mesmo assim, tais partidos se coligaram, nos dois anos, em mais de $86 \%$ das vezes, na tentativa de maximizar seus votos, conseguindo tanto ultrapassar mais vezes o quociente eleitoral como ficar bem-posicionados na disputa das sobras.

Os partidos pequenos são, proporcionalmente, os que menos se coligam. Antes de tomar conclusões precipitadas, é importante levar em consideração o comportamento dos pequenos partidos de esquerda (PCB, PCO, PSOL e PSTU), que preferem competir sozinhos nas eleições. Em 2010, eles se coligaram em apenas $22 \%$ das vezes em que concorreram e, em 2014, essa proporção chegou a apenas 35\%. Quando não são levados em consideração no cálculo final, a proporção de partidos pequenos coligados aumenta consideravelmente, passando para aproximadamente $92 \%$ nos dois anos.

Partidos médios - aqueles que não alcançam o quociente eleitoral, mas têm, no total, uma boa votação - são os que mais se coligam. Nos dois anos, quase todos os partidos médios preferiram concorrer aliados a outros partidos, e em apenas seis casos não se coligaram. Em três destes casos, os partidos chegaram perto de ultrapassar o quociente eleitoral, com mais de 85\% dos votos necessários, incluindo-se nesta soma o PSOL no Rio Grande do Sul, quando teve uma das candidatas mais votadas da disputa, Luciana Genro, mas não conseguiu ultrapassar o quociente eleitoral. Nos outros três casos, dois partidos são do PEN — nos únicos dois estados em que o partido concorreu e não se coligou.

Esses partidos médios sabem que vão receber uma boa votação, mas sabem também que há a chance de não conseguirem ultrapassar o quociente eleitoral. Para não arriscarem desperdiçar uma boa quantidade de votos e sabendo que terão boas chances de conseguirem cadeiras se participarem de coligações, eles preferem não correrem o risco de competirem sozinhos. O trabalho de Nicolau (1996, p. 76) volta à tona, segundo o qual

Nos dois extremos o comportamento é previsível: os pequenos partidos procurarão fazer alianças, enquanto os grandes não terão interesse em fazê-las. Nos casos intermediários, dos partidos que não têm segurança com relação ao seu provável desempenho eleitoral, o comportamento mais prudente é fazer coligação, evitando o risco de não atingir sozinho o quociente eleitoral. 


\section{PODER DE BARGANHA}

Em “A democracia nas urnas”, Lavareda (1991, p. 115-116) argumenta que a eleição proporcional é apenas uma das faces do jogo político. Segundo o autor,

[...] os grandes partidos aceitavam, tal como nos dias atuais, as coligações por motivos rigorosamente estranhos aos pleitos proporcionais. As coligações nesses pleitos funcionavam como instrumento de barganha para amealhar apoio de pequenas legendas nas eleições de soma zero - os pleitos majoritários de turno único para executivos estaduais (Lavareda 1991, pp.115-116)(Lavareda 1991, pp.115-116).

Nicolau (1996, p. 76) reforça esse argumento, levando em conta o HGPE. Segundo ele, "outro indicador que não pode ser desconsiderado é o poder de chantagem dos partidos: se o partido $\mathrm{X}$ tem interesse em aliar-se ao partido $\mathrm{Y}$, ele pode ameaçar apoiar o partido Z, rival do partido Y. Nesse caso, o custo de aliar-se a um partido pode ser menor do que o ver associado a um rival".

Na sua tese de doutorado, Guarnieri (2009) analisa os impactos da lei de Duverger sobre as eleições majoritárias brasileiras, e percebe uma concentração dos pleitos majoritários em poucos candidatos. Embora ele encontre um número médio de seis a sete candidatos aos governos dos estados — entre os anos de 1998 e 2006 - o número efetivo de candidatos gira ao redor de três. Em $86 \%$ dessas eleições, o número de candidatos viáveis se concentrou em três ou menos. Dessa forma, "partidos que acreditam ter poucas chances de sucesso e/ou temem favorecer seus principais adversários são estimulados a não apresentar candidaturas próprias, apoiando aliados" (LIMONGI; VASSELAI, 2016). Isso resulta em candidaturas aos governos por coligações cada vez mais extensas.

Visto isso, o esperado, portanto, é que o partido que encabeça a chapa abrigue, sob sua coligação proporcional, senão todos, uma boa parte dos aliados da eleição majoritária. A Figura 2 apresenta uma análise gráfica dessa questão. $\mathrm{O}$ gráfico superior diz respeito às eleições de 2010, e o inferior, a 2014. Os estados estão dispostos de acordo com a sua magnitude, em ordem crescente. 


\section{FIGURA 2 - PROPORÇÃO DE PARTIDOS COLIGADOS NA COLIGAÇÃO DO CABEÇA DE CHAPA ESTADUAL}

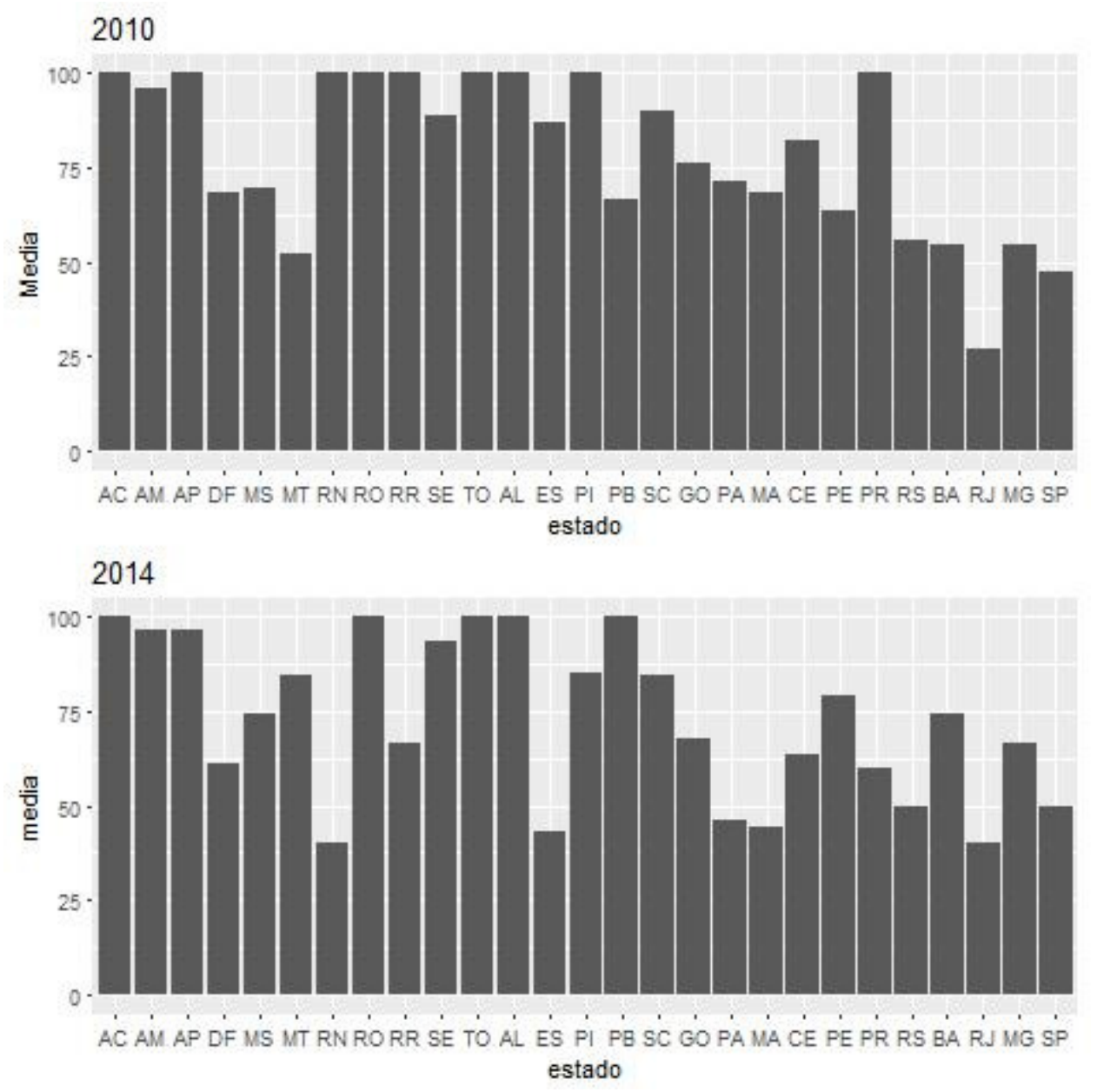

FONTE: TRIBUNAL SUPERIOR ELEITORAL.

Fica, assim, mais clara a associação entre as coligações nos diferentes níveis. As alianças para o Legislativo encabeçadas por partidos que lançam candidatos a governador tendem a abarcar a maioria das legendas que os apoiam. Em 2010, nove estados contaram com as mesmas coligações, abarcando todos os partidos nas duas esferas. Em apenas dois estados a proporção dos partidos que concorreram juntos para governador e deputado é menor do que $50 \%$, ambos em distritos com grandes magnitudes. Em apenas quatro estados elas contêm menos da metade das agremiações coligadas para o Executivo. De maneira bem discreta, é possível ver que esse comportamento é mais comum em estados com baixa magnitude, e que, quanto maiores eles são, mais dispostos a concorrerem sozinhos estão os seus partidos. Porém, é possível afirmar que há uma relativa associação entre tais coligações. Os partidos que lançam candidatos a governador abarcam, na maioria das vezes, mais da metade dos partidos das suas alianças nas coligações proporcionais. 
Em 2014 houve uma diminuição geral na ocorrência desse comportamento. A proporção de coligações proporcionais iguais às majoritárias caiu consideravelmente, e em apenas cinco estados elas se repetiram totalmente. Em movimento contrário, houve um aumento no número de estados onde essa proporção era menor do que a metade, passando de dois para seis. Se mais partidos se coligaram nesse ano e as coligações ficaram maiores, o que explica essa tendência de queda? Uma possível explicação está no movimento de partidos pequenos, que preferem montar coligações menores, com outros partidos do mesmo potencial eleitoral, ou apenas um partido grande. A razão para isso seria a inviabilidade de se posicionar um candidato do seu partido entre os mais votados em uma coligação muito grande.

\section{CONSIDERAÇÕES FINAIS}

A prática das coligações é uma estratégia usada desde a década de 40. Se no período republicano anterior ela já era uma estratégia predominante dos partidos para as eleições, na atualidade ela é uma regra. Na Câmara dos Deputados, nove de cada dez parlamentares foram eleitos por partidos coligados. Em alguns estados, se o partido não se coliga, não vence. Devido às características do nosso sistema eleitoral e da legislação vigente, é praticamente mandatória a prática de coligação.

É possível afirmar que os partidos são atores pragmáticos e agem racionalmente no sentido de evitar o desperdício de votos e manter sua representação no legislativo. Seus objetivos são alcançar o sucesso eleitoral e a conquista de cadeiras, adotando as melhores estratégias possíveis para tal. Por isso, eles se coligam mais onde é mais difícil se eleger. Em estados de baixa magnitude quase todos os partidos se coligam. As exceções são, normalmente, os pequenos partidos de esquerda, que contam com maior resistência à prática aliancista. Com o aumento da magnitude do distrito, a proporção de partidos coligados diminui. Porém, essa queda tem sido cada vez menor: de maneira geral, coligar é a regra.

Deve-se lembrar que isso não significa que as coligações sejam iguais independentemente do distrito onde elas ocorrem. O efeito majoritário é grande e pune quem não consegue lançar mão de boas estratégias. Em estados menores, onde alcançar o quociente eleitoral é relativamente mais difícil, partidos não buscam somente se coligar, mas montar grandes alianças partidárias, às vezes com todos os partidos da coligação majoritária. Uma coligação maior auxilia na ultrapassagem do quociente eleitoral um maior número de vezes, garantindo assim mais cadeiras para a coligação — e menos para os seus adversários. 
Os partidos não têm necessariamente o mesmo tamanho em todos os estados. Enquanto os partidos grandes adquirirem relevância em quase todos os distritos, diversos partidos pequenos são importantes apenas em estados específicos. $\mathrm{O}$ federalismo partidário causa uma lacuna na análise sobre coligações: como partidos grandes nas esferas estaduais se comportam? Para isso, foi feita uma classificação dos partidos na esfera estadual: partidos grandes são aqueles que ultrapassam o quociente eleitoral por conta própria e, portanto, não precisariam, em princípio, se coligar. Partidos médios não conseguem ultrapassar o quociente eleitoral sozinhos, mas obtêm uma votação relevante. Partidos pequenos são os que não alcançam nem a metade do quociente eleitoral, e não há dúvidas de que, se não se coligarem, não elegerão ninguém.

De maneira geral, todos os partidos, independentemente da sua força no estado, tendem a se coligar, respondendo, dessa forma, aos vários incentivos da legislação eleitoral e considerando o contexto da disputa que enfrentam no nível estadual. Merece destaque o comportamento dos partidos médios: eles sabem que contam com candidatos com alto potencial de votos, mas não querem correr o risco de, competindo sozinhos, não alcançarem o quociente eleitoral, e são os que mais se coligam. Como vimos, quase todos eles participam de alguma aliança.

Outro aspecto aqui tratado foi a relação entre a coligação proporcional e a majoritária. A quantidade de partidos que apresentam candidatos ao executivo estadual é bastante reduzida, e o número de partidos que competem sozinhos é ainda menor, visto que, de acordo com a legislação eleitoral, é limitada sua capacidade de montar alianças nas eleições para a Câmara dos Deputados. A articulação entre as eleições majoritária e proporcional é mais visível em 2010, quando a maioria das coligações majoritárias se repete nas eleições proporcionais. Em 2014 esse comportamento fica menos claro. Porém, nos dois anos, essa prática é mais presente em estados menores.

Esse artigo, ainda, demonstra a necessidade de se continuar com os estudos sobre o assunto. Se não sobre as coligações proporcionais, que sempre são alvos de debate quanto à sua abolição, mas teimam em persistir, sobre as outras esferas eleitorais. A memória coligacional, por exemplo, pode ser um bom caminho a ser traçado, tentando-se unir o modelo pragmático com o debate sobre a consistência das alianças — se não ideológicas, pelo menos ao longo do tempo. A abordagem ecológica, proposta por Peres e Lenine (2016), também é interessante, buscando-se entender as estratégias coligacionistas como inseridas em um ecossistema político, onde os partidos buscam uma multiplicidade de motivações. 


\section{REFERÊNCIAS}

BENOIT, K., 2000. Which Electoral Formula Is the Most Proportional? A New Look with New Evidence. Political Analysis, 8(4), pp.381-388.

BORGES, T.D.P., CARREIRÃO, Y. \& NASCIMENTO, F.P., 2016. Os partidos políticos brasileiros e a (in)consistência das coligações para deputado federal em 2014. In Coligações e disputas eleitorais na nova república. Rio de Janeiro: Fundação Konrad Adenauer, pp. 203230.

FERREIRA, C. \& RIBEIRO, M., 2010. Estratégias Partidárias em Eleições proporcionais: Uma análise do HGPE da campanha à Câmara dos Deputados no Rio Grande do Sul nas eleições de 2010. $5^{a}$ mostra de Pós-Graduação, pp.188-192.

FIGUEIREDO, M., 1994. Competição eleitoral: eleições casadas, resultados solteiros. Monitor Público, (2), pp.21-27.

FLEISCHER, D. \& DALMORO, J., 2005. Eleição proporcional: os efeitos das coligações e o problema da proporcionalidade. In Partidos e coligações eleitorais no Brasil. Rio de Janeiro: Fundação Konrad Adenauer, pp. 85-114.

GUARNIERI, F., 2009. A força dos "partidos fracos" - um estudo sobre a organização dos partidos e seu impacto na coordenação eleitoral. USP.

KRAUSE, S., 2005. Uma análise comparativa das estratégias eleitorais nas eleições majoritárias (1994-1998-2002): coligações eleitorais X nacionalização dos partidos e do sistema partidário brasileiro. In Partidos e coligações eleitorais no Brasil. Rio de Janeiro: Konrad Adenauer, pp. 115-141.

KRAUSE, S. \& GODOI, P.P.A., 2010. Coligações eleitorais para os executivos estaduais (1986-2006): padrões e rendências. In Coligações Partidárias na Nova Democracia Brasileira. São Paulo: Editora Unesp, pp. 41-98.

KRAUSE, S. \& SCHMITT, R.A., 2005. Partidos e coligações eleitorais no Brasil, Rio de Janeiro: Fundação Konrad Adenauer.

LAVAREDA, A., 1991. A democracia nas urnas: o processo partidário eleitoral brasileiro, Rio de Janeiro: IUPERJ.

LIMONGI, F. \& VASSELAI, F., 2016. Coordenando candidaturas: coligações e fragmentação partidária nas eleições gerais brasileiras. In Associação Brasileira de Ciência Política.

MACHADO, A., 2005. A lógica das coligações eleitorais. In Partidos e coligações eleitorais no Brasil. Rio de Janeiro: Fundação Konrad Adenauer. 
MACHADO, C.M. \& MIGUEL, L.F., 2011. Padrões de coesão e dispersão: Uma proposta de tipologia para coligações. Teoria \& Pesquisa, XX(2), pp.37-58.

MIGUEL, L.F. \& MACHADO, C., 2007. Um Equilíbrio Delicado: A Dinâmica das Coligações do PT em Eleições Municipais (2000 e 2004). Dados - Revista de Ciências Sociais, 50(4), pp.757-793.

MIGUEL, L.F. \& MACHADO, C.A.M., 2010. De partido de esquerda a partido do governo. O PT e suas coligações para prefeito (2000 a 2008). In Coligações Partidárias na Nova Democracia Brasileira. pp. 345-371.

MIRANDA, G.L. De, 2016. A racionalidade do cálculo coligacionista nas eleições federais e majoritárias estaduais (1990-2014). In Coligações e disputas eleitorais na nova república. Rio de Janeiro: Fundação Konrad Adenauer, pp. 163-202.

NICOLAU, J., 1996. Multipartidarismo e democracia: um estudo sobre o sistema partidário brasileiro (1985-1994).

NICOLAU, J., 2012. Sistemas eleitorais 6th ed., Rio de Janeiro: Editora FGV.

PAIVA, D., ALVES, V.S. \& BENEDITO, S.M., 2016. As coligações proporcionais e os pequenos partidos nas eleições para a Câmara de Deputados 1998-2014. In Coligações e disputas eleitorais na nova república. Rio de Janeiro: Fundação Konrad Adenauer, pp. 321339.

PERES, P. \& LENINE, E., 2016. Uma abordagem ecológica das coligações eleitorais. In Coligações e disputas eleitorais na nova república. São Paulo: Fundação Konrad Adenauer; Editora Unesp, pp. 61-92.

RAE, D., 1957. Political consequences of electoral laws, New Haven: Yale University Press. SANTOS, W.G. dos, 1987. Crise e castigo: partidos e generais na política brasileira, São Paulo: Vértice/Iuperj.

SCHMITT, R.A., 1999. Coligações eleitorais e sistema partidário no Brasil. IUPERJ.

SOARES, G., 1964. Alianças e coligações eleitorais no Brasil: notas para uma teoria. Revista Brasileira de Estudos Políticos, (17), pp.95-124.

TSE. Repositório de dados eleitorais. Disponível em: http://www.tse.jus.br/eleitor-eeleicoes/estatisticas/repositorio-de-dados-eleitorais-1/repositorio-de-dados-eleitorais 